\title{
Korelasi Nilai Komunikasi Mahasiswa Fakultas Kedokteran Universitas Padjadjaran pada OSCE Tahap Akademik dengan OSCE UKMPPD
}

\author{
Qori Lestari, ${ }^{1}$ Sari Puspa Dewi, ${ }^{2}$ Insi Farisa Desy Arya ${ }^{2}$ \\ ${ }^{1}$ Fakultas Kedokteran Universitas Padjadjaran, \\ ${ }^{2}$ Departemen Ilmu Kesehatan Masyarakat Fakultas Kedokteran Universitas Padjadjaran
}

\begin{abstract}
Abstrak
Kurangnya kemampuan komunikasi dokter dalam menyampaikan informasi kepada pasien masih menjadi masalah yang sering dikeluhkan. Objective Stuctured Clinical Examination (OSCE) merupakan salah satu alat evaluasi kemampuan komunikasi. OSCE diterapkan mulai tahap akademik dan berlanjut sampai tahap Uji Kompetensi Mahasiswa Program Profesi Dokter (UKMPPD). Penelitian ini bermaksud melihat korelasi nilai komunikasi mahasiswa pada tahap akademik dengan UKMPPD untuk mengevaluasi kurikulum komunikasi yang dilaksanakan di Fakultas Kedokteran Universitas Padjadjaran(FKUP). Metode studi potong lintang dilakukan pada nilai OSCE tahap akademik dan UKMPPD dari 264 data mahasiswa FK Unpad angkatan 2009 dan 2010 pada September - November 2015. Rerata nilai OSCE untuk komunikasi maupun nilai komponen anamnesis dan komunikasi (communication skills, drug education, breaking bad news, informed concent) dianalisis dengan uji korelasi Spearman. Hasil rerata nilai OSCE komunikasi tahap akademik dan UKMPPD secara berurutan adalah 88,77 $(+2,21)$ dan 86,33 $(+6,74)$ dengan koefisien korelasi $\mathrm{r}=0,158(\mathrm{p}<0,05)$. Untuk komponen anamnesis dan komunikasi diperoleh koefisien korelasi secara berurutan adalah $r=0,131(p<0,05)$ dan $r=0,181 \quad(p>0,05)$. Simpulan terdapat korelasi positif lemah antara nilai komunikasi OSCE tahap akademik dengan OSCE UKMPPD. Perlu dilakukan penelitian lebih lanjut mengenai pendidikan dan penilaian komunikasi yang berlangsung selama proses pendidikan profesi dokter.
\end{abstract}

Kata kunci: Komunikasi, OSCE

\section{Correlation of Communication Score between Undergraduate OSCE and UKMPPD OSCE at Faculty of Medicine Universitas Padjadjaran}

\begin{abstract}
Lack of doctor's communication skills in conveying information to the patients is still the problem in doctor patient communication. OSCE is one of tools to evaluate communication skills. OSCE has been implemented started from academic phase and continues until examined in Uji Kompetensi Mahasiswa Program Profesi Dokter (UKMPPD)/Competence Examination of Medical Graduates (CEMG). This study was aimed to know the correlation of communication score between undergraduate OSCE and CEMG OSCE to evaluate communication curriculum in Faculty of Medicine Universitas Padjadjaran (FMUP). Methods a Crosssectional study was conducted on undergraduate and CEMG OSCE score from 264 student's data batch 2009 and 2010 on September - November 2015. The Spearman correlation were used to analyze the mean score of undergraduate and CEMG OSCE as well as anamnesis and communication components (communication skills, medication education, breaking bad news, informed concent). Results the communication mean score for undergraduate OSCE and CEMG OSCE was 88.77 (+2.21) and $86.33(+6.74)$ respectively with a correlation coefficient $r=0.158(p<0.05)$. The correlation coefficient for anamnesis and communication component was $r=0.131(p<0.05)$ and $r=0.181(p>0.05)$ respectively. Discussion there are weak positive correlations between communication score on undergraduate OSCE and CEMG OSCE. Further study is needed to evaluate how the education and assessment of communication take place during the process of clinical clerkship programs.
\end{abstract}

Keywords: Communication, OSCE.

Korespondensi:

Qori Lestari

Fakultas Kedokteran Universitas Padjadjaran

Jalan Raya Bandung-Sumedang KM. 21 Jatinangor, Sumedang, Jawa Barat, Indonesia

Mobile : 082219354305

Email : qorilestari@gmail.com 


\section{Pendahuluan}

Masalah komunikasi sering kali terabaikan dalam proses pendidikan ataupun praktik profesi kedokteran. Di Indonesia kasus dugaan malpraktik yang ditangani oleh Majelis Kehormatan Disiplin Kedokteran Indonesia (MKDKI) menyebutkan $80 \%$ dari 127 kasus pengaduan disebabkan oleh kurangnya komunikasi di antara dokter dan pasien. Dugaan malpraktik tersebut paling banyak dilakukan oleh dokter umum dengan 48 angka kasus. ${ }^{1}$ Penelitian Tongue dkk. pada tahun 2005 melaporkaan bahwa $75 \%$ dokter bedah ortopedi mempercayai bahwa kemampuan komunikasi berkaitan dengan tingkat kepuasan pasien, sementara hanya $21 \%$ pasien yang merasa telah mencapai kepuasan terhadap komunikasi yang telah dilakukannya bersama dokter. ${ }^{2}$ Komunikasi efektif merupakan area kompetensi ke 3 pada Standar Kompetensi Dokter Indonesia (SKDI) 2012. ${ }^{3}$ Keterampilan komunikasi dalam pendidikan dokter diajarkan sejak tahap akademik sampai tahap profesi. $^{4,5}$ Salah satu upaya yang dilakukan untuk mengevaluasi kemampuan komunikasi mahasiswa dan keberhasilan program pendidikan adalah melalui Objective Structured Clinical Examination (OSCE). ${ }^{6}$ OSCE telah diterapkan pada pendidikan dokter di Indonesia sejak tahun 2005 dan sejak tahun 2013 telah menjadi bagian dari Ujian Kompetensi Mahasiswa Program Profesi Dokter (UKMPPD) yang diujikan secara nasional untuk menilai kemampuan calon dokter. ${ }^{6}$

Pada kurikulum pendidikan dokter di Fakultas Kedokteran Universitas Padjadjaran kemampuan komunikasi diajarkan sejak tahap akademik dan berlanjut sampai dengan tahap profesi pada Program Studi Profesi Dokter (PSPD). ${ }^{5}$ Pada tahap akademik mahasiswa belajar dengan teman atau pasien terstandar pada kegiatan keterampilan klinik, sedangkan pada PSPD mahasiswa langsung berpraktik kepada pasien., ${ }^{4,6}$ Pada akhir proses pendidikan dokter, kemampuan komunikasi merupakan salah satu topik yang akan diuji pada UKMPPD. UKMPPD yang dilaksanakan untuk melihat kualitas calon peserta ujian dan keefektifan program pendidikan kedokteran di seluruh Indonesia. ${ }^{6}$

Penilaian kemampuan komunikasi dokter dapat dilakukan melalui beberapa cara seperti Mini Clinical Examination (Mini-CEX), Objective Stuctured Clinical Examination (OSCE), Multisource Feedback (MSF), dan InTraining Evaluation Reports (ITER). ${ }^{7}$ OSCE dinilai sebagai alat yang tepat digunakan untuk melihat kemampuan komunikasi dokter karena OSCE dapat menggambarkan simulasi kondisi sebenarnya dalam melakukan praktik klinis kedokteran. ${ }^{8,9}$ OSCE merupakan metode penilaian untuk melihat kemampuan dan kompetensi yang dimiliki oleh para dokter atau calon dokter yang terdiri dari beberapa stasion dengan menggunakan pasien standar dengan waktu ujian antara 5-10 menit. Kemampuan para dokter tersebut akan dinilai oleh penguji sesuai dengan format penilaian yang telah distandarisasi. ${ }^{7}$

OSCE tahap akademik merupakan ujian akhir program yang dilaksanakan setiap akhir semester atau enam bulan sekali. Ujian OSCE dinilai sebagai alat untuk melihat keterampilan prosedur klinik yang dimiliki oleh mahasiswa. Pada pelaksanan ujian, mahasiswa akan berpindah dari satu stasion ke stasion yang lain sesuai sistem yang telah dipelajari. Masing-masing stasion diberi waktu 5-10 menit. Di dalam ruangan ujian sudah terdapat pasien dan penguji yang telah terstandarisasi.Kemudianhasilujimahasiswaakan dikonversikan ke dalam nilai mutlak dari angka 0-100. Untuk menguji kemampuan komunikasi mahasiswa, terdapat 2-4 stasion anamnesis dan komunikasi dalam setiap ujian OSCE. ${ }^{5}$

OSCE UKMPPD adalah ujian yang dilaksanakan pada akhir tahap pendidikan profesi dokter. OSCE UKMPPD merupakan metode pengujian kompetensi klinik calon dokter yang dilakukan secara objektif dan terstruktur diujikan dalam waktu 15 menit dengan bentuk putaran stasion. Pada masing-masing stasion terdapat tugas atau soal yang harus dipraktikkan dan pertanyaan yang harus dijawab. Di dalam ruangan peserta akan diobservasi oleh penguji. Setiap stasion memiliki materi uji yang berbeda dengan stasion lainnya, materi yang diuji pada saat UKMPPD berdasar kepada SKDI. Sistem penilaian OSCE UKMPPD berdasar pada keputusan yang bersifat menyeluruh dari berbagai komponen penilaian. Untuk menilai kemampuan komunikasi para calon dokter terdapat penilaian terhadap komponen anamnesis serta komunikasi dan edukasi kepada pasien pada lembar penilaian di setiap stasion uji. ${ }^{10}$

Kemampuan anamnesis dinilai berdasarkan kemampuan peserta uji untuk menanyakan keluhan utama, riwayat penyakit sekarang dan terdahulu, riwayat pengobatan sebelumnya, riwayat keluarga, dan faktor lain yang berhubungan dengan penyakit pasien. Untuk kemampuan komunikasi dan edukasi kepada pasien dinilai berdasarkan kemampuan peserta uji melakukan komunikasi yang baik dalam hal membina interaksi yang baik, menggunakan bahasa yang dimengerti, memberikan penyuluhan yang tepat sesuai masalah pasien, dan menanggapi segala pertanyaan pasien dengan baik. ${ }^{10}$

Penelitian ini bertujuan untuk mengetahui korelasi nilai komunikasi mahasiswa Fakultas 
Kedokteran Universitas Padjadjaran pada OSCE tahap akademik dengan OSCE UKMPPD dengan tujuan untuk mengevaluasi kurikulum komunikasi di FKUP.

\section{Metode}

Penelitian ini merupakan penelitian analitik korelatif dengan desain potong lintang yang dilakukan pada bulan September $\square$ November 2015 di FKUP. Subjek penelitian ini adalah data nilai OSCE PSK dan nilai OSCE UKMPPD peserta FKUP angkatan tahun 2009 dan 2010. Pelaksanaan OSCE sebagai bagian dari UKMPPD dimulai sejak tahun 2013 sehingga nilai angkatan 2009 dan 2010 dipilih sebagai sampel karena termasuk kedalam peserta UKMPPD yang telah mengikuti OSCE. Kriteria inklusi OSCE tahap akademik adalah nilai OSCE Mahasiswa Warga Negara Indonesia (WNI), ujian yang pertama kali, pada stasion anamnesis dan aspek komunikasi pada semua sistem pembelajaran. Kriteria eksklusi adalah nilai OSCE yang tidak lengkap. Nilai OSCE yang tidak lengkap adalah nilai OSCE mahasiswa yang tidak hadir saat ujian, nilai mahasiswa yang tidak hadir pada saat remedial, atau nilai mahasiswa yang lulus tidak tepat waktu. Kriteria inklusi OSCE UKMPPD adalah nilai OSCE mahasiswa WNI, nilai ujian OSCE yang pertama kali, komponen anamnesis serta komunikasi dan edukasi kepada pasien pada setiap stasion uji. Dengan menggunakan total sampling setelah dilakukan olah kriteria data inklusi dan ekslusi didapat 264 data nilai yang masuk kedalam penelitian ini dari jumlah seluruh data sebanyak 378 data nilai mahasiswa FKUP. Terdapat 34 data tidak lengkap dan 80 mahasiswa tidak lulus tepat waktu yang masuk kedalam kriteria eksklusi. Variabel bebas pada penelitian ini adalah nilai komunikasi OSCE tahap akademik, yaitu nilai OSCE pada saat ujian pertama yang didapatkan dari stasion history taking dan aspek komunikasi mulai dari tahun pertama sampai tahun ke-4 untuk semua sistem pembelajaran. Variabel terikat pada penelitian adalah nilai komunikasi OSCE UKMPPD, yaitu nilai OSCE peserta ujian pada saat pertama UKMPPD pada komponen penilaian anamnesis serta komunikasi dan edukasi kepada pasien di setiap stasion uji.

Nilai OSCE tahap akademik terdiri dari stasion history taking pada sistem reproduksi, sistem endokrin dan metabolisme, neurobehavioral and special senses system, dermatomusculosceletal system, hematology and immunology system, cardiovascular system, respiratory system, gastro-intestinal system, genitor-urinary system, family medicine and tropical medicine system. Nilai OSCE pada UKMPPD adalah nilai aspek komunikasi yang terdiri dari stasion communication skills, drug education, informed concent, dan breaking bad news.

Penelitian ini menggunakan analisis korelasi bivariat dengan menggunakan korelasi Spearman karena sebaran data tidak normal. Apabila korelasi perhitungan nilai $\mathrm{p}<0,05$ maka korelasi dianggap signifikan. Korelasi dianggap positif jika koefisien relasi $r>0,00$. Korelasi dianggap lemah jika $\mathrm{r}=0,1-0,3$; sedang jika $r=0,4-0,5$ dan kuat jika $r>0,5.11,12$

Penelitian ini telah mendapatkan persetujuan dari Komite Etik Penelitian Kesehatan Universitas Padjajaran Fakultas Kedokteran.

\section{Hasil}

Berdasarkan data nilai OSCE yang diperoleh dari 264 sampel Mahasiswa FK Unpad angkatan 2009-2010 didapat hasil sebagai berikut:

Tabel 1 Karakteristik Data Mahasiswa FK Unpad Angkatan 2009--2010

\begin{tabular}{lcc}
\hline \multicolumn{1}{c}{ Karakteristik Sampel } & Jumlah n=264 & Presentasi (\%) \\
\hline Jenis kelamain & 82 & $31,10 \%$ \\
Laki-laki & 182 & $68,90 \%$ \\
Perempuan & & \\
IPK & 48 & $18,20 \%$ \\
$2,00-3,00$ & 155 & $58,70 \%$ \\
$3,00-3,50$ & 41 & $23,10 \%$ \\
$3,50-4,00$ & & \\
Periode UKMPPD & 122 & $46,20 \%$ \\
November 2014 & 142 & $53,80 \%$ \\
Agustus 2015 & &
\end{tabular}


Tabel 2 Nilai Rerata OSCE Tahap Akademik dan OSCE UKMPPD (Rerata Anamnesis dan Komunikasi)

\begin{tabular}{ccccc}
\hline \multirow{2}{*}{$\begin{array}{c}\text { Nilai OSCE } \\
(\mathbf{I K}=\mathbf{9 5 \%})\end{array}$} & \multicolumn{2}{c}{ Tahap Akademik } & \multicolumn{2}{c}{ UKMPPD } \\
\cline { 2 - 5 } $2009(\mathrm{n}=122)$ & Mean $( \pm$ SD) & Rentang & Mean $( \pm$ SD) & Rentang \\
$2010(\mathrm{n}=142)$ & $89,05(2,28)$ & $83,08-94,15$ & $85,54(6,74)$ & $53,80-1,00$ \\
Total $(\mathrm{n}=264)$ & $88,54(2,13)$ & $81,56-94,00$ & $87,01(5,20)$ & $64,10-98,70$ \\
\hline
\end{tabular}

Tabel 1 menunjukkan bahwa jumlah peserta ujian perempuan lebih banyak dibandingkan laki-laki. Mayoritas peserta ujian memiliki nilai Indeks Prestasi Kumulatif (IPK) di atas 3,00. Tabel 2 menunjukkan bahwa rerata yang diperoleh di OSCE tahap akademik lebih besar dibandingkan rerata yang diperoleh di OSCE UKMPPD. Untuk OSCE tahap akademik angkatan 2009 memperoleh nilai rerata terbesar sedangkan pada OSCE UKMPPD rerata terbesar diperoleh angkatan 2010. Tabel 3 menunjukkan rerata nilai OSCE komponen anamnesis dan komunikasi tahap akademik mempunyai rerata yang lebih besar dibandingkan dengan nilai pada OSCE UKMPPD. Nilai rerata tertinggi pada komponen anamnesis dan komunikasi pada OSCE tahap akademik dan OSCE UKMPPD diperoleh oleh angkatan 2010. Tabel 4 menunjukan bahwa dari 264 sampelnilai OSCE angkatan 2009 dan angkatan 2010 yang telah diuji dengan mengggunakan analisis Spearman didapatkan koefisien korelasi $\mathrm{r}=0,158$ dengan $\mathrm{p}=0,01$ menunjukkan adanya korelasi lemah yang signifikan diantara nilai OSCE tahap akademik dengan OSCE UKMPPD. Pada komponen Anamnesis OSCE tahap akademik dan OSCE UKMPPD diperoleh koefisien korelasi $r=0,131$ dengan $p=0,033$ menunjukkan adanya korelasi yang signifikan di antara kedua nilai. Koefisien korelasi komponen komunikasi tahap akademik dan OSCE UKMPPD adalah $\mathrm{r}=0,181$ dengan $\mathrm{p}=0,190$ menunjukkan tidak terdapat adanya korelasi diantara kedua nilai. ${ }^{11,12}$

\section{Pembahasan}

Penelitian ini dilakukan untuk menginvestigasi korelasi antara nilai komunikasi mahasiswa FKUP angkatan 2009-2010 pada OSCE tahap akademik dan OSCE UKMPPD. Terdapat dua hasil temuan, pertama korelasi antara nilai OSCE tahap akademik (rerata nilai gabungan komponen anamnesis dan komunikasi) dan OSCE UKMPPD (rerata nilai gabungan komponen anamnesis serta komunikasi dan edukasi pasien). Kedua, korelasi masing-masing komponen anamnesis OSCE tahap akademik dengan anamnesis OSCE UKMPPD dan komunikasi OSCE tahap akademik dengan komunikasi OSCE UKMPPD.

Pelaksaan OSCE pada tahap akademik dan UKMPPD berbeda. Pada OSCE tahap akademik kemampuan komunikasi hanya terdapat dalam beberapa stasion saja berdasarkan kemampuan mahasiswa melakukan tugas pada stasion history taking dan komunikasi dengan menggunakan penilaian checklist score sedangkan pada OSCE UKMPPD kemampuan komunikasi dinilai pada semua stasion uji dengan menggunakan penilaian global rating scale (GRS), ${ }^{5,10}$ Penilaian dengan menggunakan checklist score ataupun global rating scale (GRS) tidak memiliki perbedaan

Tabel 3 Nilai Rerata Komponen Anamnesis dan Komunikasi pada OSCE Tahap Akademik dan OSCE UKMPPD

\begin{tabular}{lllll}
\hline \multirow{2}{*}{$\begin{array}{c}\text { Nilai OSCE } \\
(\text { IK=95\%) }\end{array}$} & \multicolumn{2}{c}{ Tahap Akademik } & \multicolumn{2}{c}{ UKMPPD } \\
\cline { 2 - 5 } & $\begin{array}{c}\text { Anamnesis } \\
\text { Mean( } \pm \text { SD) }\end{array}$ & $\begin{array}{c}\text { Komunikasi } \\
\text { Mean }( \pm \text { SD) }\end{array}$ & $\begin{array}{c}\text { Anamnesis } \\
\text { Mean }( \pm \text { SD) }\end{array}$ & $\begin{array}{c}\text { Komunikasi } \\
\text { Mean( } \pm \text { SD) }\end{array}$ \\
\hline $2009(\mathrm{n}=122)$ & $88,39(2,49)$ & $90,50(3,58)$ & $85,05(7,86)$ & $86,03(7,72)$ \\
$2010(\mathrm{n}=142)$ & $88,48(2,44)$ & $88,67(2,92)$ & $90,09(7,29)$ & $87,76(7,38)$ \\
Total $(\mathrm{n}=264)$ & $88,44(2,46)$ & $89,53(3,36)$ & $87,76(7,38)$ & $85,02(7,54)$ \\
\hline
\end{tabular}


Tabel 4 Korelasi Komponen Anamnesis dan Komunikasi pada OSCE Tahap Akademik dengan OSCE UKMPPD

\begin{tabular}{lcc}
\hline Nilai Korelasi (IK=95\%) & $\mathbf{r}$ & $\mathbf{p}$ \\
\hline $\mathbf{2 0 0 9}(\mathbf{n}=\mathbf{1 2 2})$ & & \\
Anamnesis OSCE akademik - OSCE UKMPPD & 0,257 & $0,004^{*}$ \\
Komunikasi OSCE akademik - OSCE UKMPPD & 0,125 & 0,170 \\
$\mathbf{2 0 1 0}(\mathbf{n}=\mathbf{1 4 2})$ & & \\
Anamnesis OSCE akademik - OSCE UKMPPD & 0,083 & 0,324 \\
Komunikasi OSCE akademik - OSCE UKMPPD & 0,043 & 0,613 \\
Total (n= 264) & & \\
OCSE akademik- OSCE UKMPPD & 0,158 & $0,01^{*}$ \\
Anamnesis OSCE akademik - OSCE UKMPPD & 0,131 & $0,033^{*}$ \\
Komunikasi OSCE akademik - OSCE UKMPPD & 0,181 & 0,190 \\
\hline Stastistical Test Used Spearman's Correlation* $=<0,05$ & &
\end{tabular}

yang terlalu jauh, kedua alat penilaian ini memiliki validitas dan reliabilitas yang sama sehingga tidak berpengaruh pada penelitian ini. ${ }^{13}$

Penelitian yang dilakukan oleh Dong dkk pada tahun 2012 menyatakan bahwa terdapat korelasi kuat dengan $\mathrm{r}=0.71(\mathrm{p}=<0.05)$ antara nilai OSCE undergraduate terhadap nilai pada ujian United States Medical Licensing Examination (USMLE) tahap 2. USMLE adalah sebuah ujian seperti UKMPPD yang dilakukan untuk melihat kualitas dokter di Amerika Serikat. USMLE tahap 2 merupakan ujian yang dilakukan untuk menilai kemampuan klinis para calon dokter. ${ }^{14}$ Hasil penelitian tersebut tidak sejalan dengan penelitian ini karena hasil analisis yang didapatkan dari data nilai OSCE PSK dan OSCE UKMPPD yang telah diuji menggunakan uji Spearman, diperoleh $r=0,158$ dan $p=0,01$. Nilai tersebut menunjukan bahwa terdapat korelasi positif lemah yang signifikan di antara kedua nilai.

Hasil analisis 264 data nilai OSCE PPSK dan OSCE UKMPDD pada komponen anamnesis diperoleh $r=0,131$ dan $p=0,033$. Nilai tersebut menunjukan bahwa terdapat adanya korelasi positif lemah yang signifikan diantara kedua nilai. ${ }^{12}$ Hasil penelitian tersebut sejalan dengan penelitian sebelumnya yang menunjukan bahwa terdapat korelasi lemah antara kemampuan komunikasi OSCE undergraduate terhadap kemampuan komunikasi OSCE USMLE. ${ }^{15}$ Sebaliknya untuk komponen komunikasi tidak terdapat korelasi karena diperoleh nilai p sebesar 0,190 dan $r$ sebesar $0,181 . .^{11,12}$

Faktor-faktor yang menyebabkan lemahnya korelasi antara nilai OSCE tahap akademik dan OSCE UKMPPD pada penelitian ini kemungkinan disebabkan oleh kondisi pasien standar/standardized patient (SP). ${ }^{14,16}$ Studi yang dilakukan oleh Kilminster S, Roberts
T, Morris P dari University of Leeds, Leeds, UK pada tahun 2007 menyebutkan reliabilitas penggunaan SP dalam OSCE sebesar 0,77. Hal tersebut menunjukkan bahwa SP merupakan alat bantu yang layak dalam menilai kemampuan mahasiswa dalam OSCE. Berdasarkan penelitian itu kemampuan SP dalam mempresentasikan keadaan penyakit sesuai dengan kondisi sebenarnya akan berpengaruh terhadap hasil yang diperoleh mahasiswa dalam OSCE. ${ }^{17}$

Studi yang dilakukan oleh Berg dkk. pada tahun 2008 menyebutkan bahwa koefisien korelasi antara kemampuan komunikasi tahap akademik dengan kemampuan komunikasi pada USMLE tahap-2 adalah $\mathrm{r}=0,32 \quad(\mathrm{p}<0,05)$ menunjukan adanya korelasi lemah diantara kedua nilai. Lemahnya korelasi diperkirakan disebabkan oleh jeda waktu yang terlalu lama diantara kedua ujian sehingga terjadi penurunan nilai tes dikarenakan kurangnya observasi selama proses praktik klinis.

Kemampuan institusi pendidikan dalam menciptakan suasana OSCE sesuai dengan kondisi sebenarnya dapat menentukan hasil nilai yang diperoleh mahasiswa. Studi yang dilakukan oleh Prathibha dkk. menyebutkan bahwa untuk melaksanakan ujian OSCE diperlukan berbagai persiapan mulai dari dana untuk pelatihan SP, dana untuk pencarian SP, dana untuk alat simulasi, dan koordinasi waktu yang tepat untuk pelaksanaan OSCE. ${ }^{18}$

Proses pembelajaran komunikasi di PSK FKUP di antaranya adalah pembelajaran melalui skills laboratory yang dilakukan satu kali dalam seminggu. ${ }^{5}$ Kurangnya waktu yang didapatkan untuk pembelajaran komunikasi menuntut mahasiswa dapat belajar secara mandiri untuk meningkatkan kemampuan komunikasi pada saat OSCE maupun praktik kepada pasien. Proses pembelajaran mandiri akan berpengaruh terhadap 
nilai yang akan diraih mahasiswa. Setiap individu memiliki keinginan untuk belajar mandiri yang berbeda sehingga nilai komunikasi yang didapatkan pada saat ujianpun akan beragam. Proses belajar mandiri dapat dipengaruhi oleh kemampuan mahasiswa dalam mengatur waktu dan mengontrol waktu belajar serta motivasi mahasiswa dalam memperoleh pengetahuan. ${ }^{19}$ Masukan dan arahan dari penguji segera setelah dilakukan OSCE dapat membantu mahasiswa dalam mencapai nilai dan tujuan OSCE yang sesuai dengan pemahaman kaidah keilmuan. Studi yang dilakukan oleh Aeder dkk. pada tahun 2007 menyebutkan bahwa 61\% dari dokter yang sedang menjalani pendidikan spesialis di Maimonides Medical Center mengatakan mendapatkan ilmu yang baru ketika diberikan masukan oleh penguji setelah OSCE. ${ }^{20}$ Pada penelitian ini bagaimana proses komunikasi yang berlangsung selama pendidikan profesi dokter tidak diobservasi sehingga kemampuan komunikasi mahasiswa belum terpantau secara keseluruhan. Selain itu terdapat nilai mahasiswa yang tidak lengkap yang disebabkan oleh ketidakhadiran mahasiswa dalam ujian ataupun mahasiswa harus mengulang ujian karena tidak lulus.

Simpulan penelitian ini adalah terdapat korelasi positif lemah yang signifikan antara nilai komunikasi mahasiswa FKUP angkatan 20092010 pada OSCE tahap akademik dengan OSCE UKMPPD. Berdasarkan hasil penelitian ini perlu dilakukan penelitian lebih lanjut mengenai bagaimana pendidikan dan penilaian komunikasi yang berlangsung selama proses pendidikan profesi dokter. Pemberian masukan dari penguji sesegera setelah OSCE sebaiknya dilakukan untuk meningkatkan kemampuan komunikasi mahasiswa serta perbaikan terhadap pelaksanaan pembelajaran skills laboratory perlu ditingkatkan sehingga nilai komunikasi mahasiswa pada tahap akademik dan tahap UKMPPD memiliki korelasi yang lebih baik.

\section{Daftar Pustaka}

1. Konsil Kedokteran Indonesia. Dugaan Pelanggaran Disiplin Terbanyak Akibat Kurangnya Komunikasi Dokter dan Pasien. [cited 2015 December 5]. Available from: http://www.depkes.go.id/article/print/1519/ dugaan-pelanggaran-disiplin-terbanyakakibat-kurangnya-komunikasi-dokter-danpasien.html.

2. Tongue JR, Epps HR, Forese LL. Communication skills for patient-centered care. The Journal of Bone \& Joint Surgery.
2005;87(3):652-8.

3. Konsil Kedokteran Indonesia. Standar kompetensi dokter Indonesia. Jakarta: Penerbit Konsil Kedokteran Indonesia. 2012.

4. Wallenstein J, Heron S, Santen S, Shayne P, Ander D. A Core Competency-based Objective Structured Clinical Examination (OSCE) Can Predict Future Resident Performance. Academic Emergency Medicine. 2010;17(s2):S67-71.

5. Fakultas Kedokteran Universitas Padjadjaran .Pedoman Penyelenggaraan Pendidikan Fakultas Kedokteran Universitas Padjadjaran Tahun Akademik 2014/2015. 2012 [5 Mei 2015]. [cited 2015 December 4] Available from: http://www.unpad.ac.id/wp-content/ uploads/2012/07/03-FKEDOKTERAN.pdf.

6. Indonesian Medical Student Executive Broad's Association. Kajian UKDI oleh ISMKI. 2014 [cited 2015 February 23]. Available from: http://ismki.org/wp-content/ uploads/2014/05/Kajian-UKDI-oleh-ISMKI. pdf.

7. Sherbino J, Bandiera G, Frank JR. Assessing competence in emergency medicine trainees: an overview of effective methodologies. CJEM. 2008;10(04):365-71.

8. Glenn Posner M. Assessing residents communication skills: disclosure of an adverse event to a standardized patient. J Obstet Gynaecol Can. 2011;33(3):262-8.

9. Ilic D. Assessing competency in Evidence Based Practice: strengths and limitations of current tools in practice. BMC medical education. 2009;9(1):53.

10. Panitia Nasional UjiKompetensi Mahasiswa Program Profesi Dokter.

Panduan Uji Kompetensi Mahasiswa Program Profesi Dokter(UKMPPD). 2015 [cited 2015 December 4]. Available from:https://drive.google.com/file/ d/0B9bAI23gBxoANGZUYnYzUFdVVDg/ view? usp=sharing.

11. Sopiyudin DM. Langkah-langkah Membuat Proposal Penelitian Bidang Kedokteran dan Kesehatan. Jakarta: CV Sagung Seto. 2008.

12. British Medical Journal. 11. Correlation and regression [cited 2015 December 2]. Available from: http://www.bmj.com/ about-bmj/resources-readers/publications/ statistics-square-one/11-correlation-andregression.

13. Kim J, Neilipovitz D, Cardinal P, Chiu M. A comparison of global rating scale and checklist scores in the validation of an evaluation tool to assess performance in the resuscitation of critically ill patients during simulated emergencies (abbreviated as 
"CRM simulator study IB"). Simulation in Healthcare. 2009;4(1):6-16.

14. Dong T, Saguil A, Artino Jr AR, Gilliland WR, Waechter DM, Lopreaito J, et al. Relationship between OSCE scores and other typical medical school performance indicators: a 5-year cohort study. Military medicine. 2012;177(9S):44-6.

15. Berg K, Winward M, Clauser BE, Veloski JA, Berg D, Dillon GF, et al. The relationship between performance on a medical school's clinical skills assessment and USMLE Step 2 CS. Academic Medicine. 2008;83(10):S3740.

16. Ryan CA, Walshe N, Gaffney R, Shanks A, Burgoyne L, Wiskin CM. Using standardized patients to assess communication skills in medical and nursing students. BMC medical education. 2010;10(1):24.

17. Kilminster S, Roberts T, Morris P.
Incorporating patients' assessments into objective structured clinical examinations. Education for Health. 2007;20(1):6.

18. Varkey P, Natt N, Lesnick T, Downing S, Yudkowsky R. Validity evidence for an OSCE to assess competency in systems-based practice and practice-based learning and improvement: a preliminary investigation. Academic Medicine. 2008;83(8):775-80.

19. Loyens SM, Magda J, Rikers RM. Selfdirected learning in problem-based learning and its relationships with self-regulated learning. Educational Psychology Review. 2008;20(4):411-27.

20. Aeder L, Altshuler L, Kachur E, Barrett S, Hilfer A, Koepfer S, et al. The" Culture OSCE"-Introducing a formative assessment into a postgraduate program. Education for Health. 2007;20(1):11. 